\title{
Molar Pregnancy-Case report
}

\author{
Marina Yuabova* \\ La Guardia Community College, City University of New York, NY, USA
}

\begin{abstract}
Molar pregnancy is formed as a result of divergent fertilization process that leads to production of atypical tissue within the uterus. It categorized in two groups: partial and complete.

Complete mole involves absence of the embryo, where partial mole demonstrates presence of fetal parts. Molar pregnancy does not result in viable fetus, early detection and treatment is essential for positive outcome.

Patient has presented with typical signs and symptoms for molar pregnancy including vaginal spotting with dark brown grape like substance, law hemoglobin, fundal height greater then expected (as for gestational age), nausea and vomiting.

Writer will present case of molar pregnancy, risk factors, typical presentation and treatment modality.
\end{abstract}

\section{Introduction}

Hydatidiform mole is a product of anomalous conceptions, with prevalence about 1 in 500-1000 pregnancies [6]. All cases could be categorized in to two groups, complete or partial hydatidiform mole. In complete molar pregnancy diffuse swelling of chorionic villi and disseminated thromboplastic hyperplasia without embryo or fetal tissues is characteristic. These cases commonly have a diploid karyotype [4]. In opposite, partial molar pregnancy displays central swelling of the chorionic villi and thromboplastic hyperplasia. Some parts of fetal and embryonic tissues are commonly present [7]. All molar pregnancies included defective ovum flawed maternal chromosomal deoxyribonucleic acid, suggesting only of hydatidiform mole has been identified, one of which is advanced maternal age and history of previous molar pregnancies [7]. Despite the fact there are some evidence accessible in regards to definitive risk of consecutive hydatidiform moles after previous partial or complete moles $[3,5]$. In cases where fetuses with partial moles are pinpointed, they consistently bear association with congenital anomalies, such as cleft lip and syndactyly [5].

\section{Case Report}

A 19-year-old female patient reported to OB-GYN clinic for annual examination during the initial interview she complained of very unusual menstrual bleeding, which began 3 days ago, patient has also reported abdominal cramping, nausea, vomiting and lower back pain. Patient admitted to be sexually active but was using calendar method as birth control. Her last menstrual period was exactly 5 weeks ago. Patients past medical and family history are unremarkable. She denied to have any allergies, denied drinking alcoholic beverages but admitted to be an active smoker; she currently smokes 0.5 packs of cigarettes per day. The patient was alert, oriented and in obvious distress. Her temperature was $98.6 \mathrm{~F}$, blood pressure $119 / 64 \mathrm{mmHg}$, heart rate 123 $\mathrm{bpm}$, respiratory rate of 16 breaths per min with a pulse oximetry of $98 \%$ on room air. On physical exam her skin was cool and clammy and patient's breathing was mildly labored, with thread peripheral pulses.
Her fundal height was $2 \mathrm{~cm}$ below umbilicus. Abdomen was soft and mildly tender on lower quadrants bilaterally. Her lower extremities were WNL. During Pelvic examination reported loose discharge of blood, clots and a large amount of brown-colored grapelike material. The cervical OS was dilated to approximately $2 \mathrm{~cm}$ with some cervical motion tenderness.

After patient has been transferred to ER blood was collected and sent to lab for analysis, laboratory results as follows: hemoglobin of $8.6 \mathrm{~g} / \mathrm{dL}$, hematocrit of $7.5 \%$, white blood count at 16,000 with $78 \%$ neutrophils and $5 \%$ bands, platelets at 123,000 , international normalized ratio of 1.5 , and bicarbonate of $14 \mathrm{mmol} / \mathrm{L}$. Bun was elevated at $38 \mathrm{mg} / \mathrm{dL}$ and creatinine was $0.7 \mathrm{mg} / \mathrm{dL}$. Beta HCG was $360,514 \mathrm{mIU} / \mathrm{mL}$.

IV line was initiated; patient has received $1000 \mathrm{cc}$ bolus of $0.9 \%$ of sodium chloride, which followed with infusion rate at $125 \mathrm{cc}$ per hour. Case has been discussed with OB consult and Pelvic Sonogram was performed. Pelvic- sonogram reviled a cloud like image, with absence for heartbeat. Patient was transferred to OR rapidly and two units of crossed matched blood were infused. Dilatation and curettage was performed in OR.

Surgical pathology confirmed a complete hydatidiform mole. Patient's recovery was unremarkable; patient was discharged home after 48 hours. The patient was instructed on importance of using reliable method of birth control and monitoring of levels of HCG (first 48 hours post evacuation, weekly until hcg $<5 \mathrm{miu} / \mathrm{ml}$, then monthly $\mathrm{X}$ 6-12 months).

${ }^{*}$ Correspondence to: Marina Yuabova, Assistant Professor, La Guardia Community College, City University of New York, NY, USA, E-mail: marinayuabova@yahoo.com

Key words: moles, hydatidiform moles, molar pregnancy

Received: August 15, 2018; Accepted: August 23, 2018; Published: August 29, 2018 


\section{Discussion}

Molar pregnancies are classified as nonviable conceptions and are medically termed hydatidiform moles [3]. They are masses of cysts or benign tumors with a grape-like appearance that grow rapidly in the womb [3]. The abnormality is caused by a problem at conception, manifested by an excessive presence of placenta with little or no fetal development [10].

Hydatidiform moles are the most common form of benign gestational trophoblastic disease [4]. Often fatal in past centuries, significant medical advances in recent years now permit most women with moles to be cured [6].

Depending on the imbalance of genetic material in the pregnancy, the two major types of hydatidiform moles are classified as either complete or partial [1].

Forming when the sperm fertilizes an egg having no chromosomal or genetic material, a complete molar pregnancy is characterized by the presence of the placenta without an embryo [3].

Normally, the fertilized ovum would die and not implant itself in the womb [3]. In rare instances, this egg implants, triggering the growth of the placenta and the production of human chorionic gonadotrophin (HCG), the pregnancy hormone, therefore all symptoms of pregnancy will be present [5].

Partial-molar pregnancies are formed when; a normal ovum is fertilized by two sperms [3-5]. Instead of forming twins, the excessive presence of chromosomal material and trophoblastic tissue prevents normal fetal development [3]. The fetus does not survive more than three months and dies in the uterus [5-7].

As moles are rare, epidemiological studies vary in reporting incidences [6]. Vassilakos [11] states that the frequencies of moles vary by race and occur more among Asian women. Age is a known factor as higher rates of moles occur in women over the age of 40 and under the age of $20[4,5,8,11]$, as well as in women under 16 and over 50 [10].

Women with either mole type have symptoms of vaginal bleeding, nausea and vomiting, and can present hyperthyroidism or preeclampsia [1-5].

\section{Diagnosis}

Routine first trimester ultrasound examination can identify partial or complete molar pregnancy. The most of cases present as missed pregnancy during ultrasonic examination [10]. Histopathological examinations of products of conception are presently gold standard for diagnosis of gestational molar pregnancy. Abnormally high HCG blood levels and overly large uterine size suggestive of molar pregnancy and will warrant further clinical evaluation [2].

\section{Management}

Patients who are diagnosed with molar pregnancy must be evaluated for possible complications such as: overactive thyroid, anemia, and toxemia of pregnancy. Patients should have a complete examination and laboratory testing [6].

After any medical complications have been addressed, a decision must e made concerning the best method of evacuation. Suction curettage is the optimal method of evacuation, regardless of uterine size, in patients who wish to retain reproductive function, because it carries a significantly lower risk of excessive bleeding, infection, and retained molar tissue then methods involving induction with oxytocin or prostaglandin. Rh immune globulin should be given to patient with RH conflict [7].

Patients are monitored to prevent the recurrence of benign moles and the development of malignant neoplasia, which can metastasize to the brain, liver or lungs [3]. Chest x-rays and the analysis of HCG levels for six months to one year are necessary [5]. Recurring moles are treated with methotrexate, a low-level chemotherapy [7].

The American College of Obstetricians and Gynecologists has recommended that after evacuation of a mole, serum HCG levels should be monitored every 1-2 weeks in all patients while the levels are elevated and then at monthly intervals for an additional 6 months once the levels become undetectable (5MIU per milliliter) [9].

\section{References}

1. Dey M, Dhawan M (2011) Critical care management of molar pregnancy in a peripheral set-up. Med J Armed Forces India 67: 385-387. [Crossref]

2. Hydatidiform mole and choriocarcinoma UK information and support service. (2013 July 1). Retrieved August 9, 2014, from http://www.hmole-chorio.org.uk/faqs.html

3. Harding M (2013, October 18) Hydatidiform mole | Health | Patient.co.uk. Retrieved August 12, 2014, from http://www.patient.co.uk/health/hydatidiform-mole

4. Hernandez E (2013, October 7) Gestational trophoblastic neoplasia. Retrieved August 10, 2014, from http://emedicine.medscape.com/article/279116-overview

5. Hill A (2011, July 26) Molar pregnancy. Retrieved August 15, 2014, from http://www. obgyn.net/molar-pregnancy

6. Lurain JR (2010) Gestational trophoblastic disease I: Epidemiology, pathology, clinical presentation and diagnosis of gestational trophoblastic disease, and management of hydatidiform mole. Am J Obstet Gynecol 203: 531-539. [Crossref]

7. Molar pregnancy - NHS Choices (2012, September 18) Retrieved August 9, 2014, from http://www.nhs.uk/conditions/Molar-pregnancy/Pages/Introduction.aspx

8. Moore LE, Hernandez E (2012, January 30) Hydatidiform mole. Retrieved August 9, 2014, from http://emedicine.medscape.com/article/254657-overview

9. Ross S, Berkowitz M, Goldstein DP (2009). Molar pregnancy. The new England Journal of Medicine, 360 .

10. Sebire, N. J., \& Seckl, M. J. (2008). Gestational trophoblastic disease: Current management of hydatidiform mole. British Medical Journal, 337 (aug15 1), 453-458. doi:10.1136/bmj.a1193

11. Vassilakos, P. (2012, August 17). Pathology of molar pregnancy. Retrieved August 9 , 2014, from http://www.gfmer.ch/Books/Reproductive health/Mole.html

Copyright: $(2018$ Yuabova M. This is an open-access article distributed under the terms of the Creative Commons Attribution License, which permits unrestricted use, distribution, and reproduction in any medium, provided the original author and source are credited. 